\title{
Química orgánica e química macromolecular
}

\author{
Massimo Lazzari \\ Marina Nieto Suárez \\ Departamento de Química Física \\ Facultade de Química
}

unidadesdidácticas 
(C) Universidade de Santiago de Compostela, 2014

\section{Deseño e maquetación}

J. M. Gairí

Edita

Vicerreitoría de Estudantes,

Cultura e Formación Continua

da Universidade de Santiago de Compostela

Servizo de Publicacións

da Universidade de Santiago de Compostela

\section{ISBN}

978-84-16183-40-1 


\section{MATERIA: Química}

TITULACIÓN: Grao en Física

PROGRAMA XERAL DO CURSO

Localización da presente unidade didáctica

\section{Unidade 1. PROPIEDADES DA MATERIA}

Introdución aos problemas dos que se ocupa a química: materia e transformacións.

Átomo, elementos químicos. Táboa periódica.

O concepto de Mol e o número de Avogadro.

Compostos químicos: formulación e nomenclatura.

Propiedades periódicas: tamaño, ionización electrónica, afinidade electrónica.

Estrutura atómica: interpretación e representación dos orbitais.

Átomos polielectrónicos: configuración electrónica.

\section{Unidade 2. AS REACCIÓNS QUÍMICAS}

Reaccións en disolución, cálculo de concentracións, reactivo limítante.

Reaccións ácido-base, de precipitación, redox.

Axuste de reaccións redox.

\section{Unidade 3. ENLACE QUÍMICO}

Estruturas de Lewis. Formas das moléculas. Enerxías de enlace. Hibridación. Teoría de orbitais moleculares.

Líquidos, sólidos e forzas intermoleculares (funcións potencial de interacción).

\section{Unidade 4. FUNDAMENTOS DE EQUILIBRIO QUÍMICO}

Constantes de equilibrio químico. Lei de Le Chatelier.

Criterios de espontaneidade (Entropía, Entalpía e Enerxía de Gibbs).

Coeficientes de actividade.

\section{Unidade 5. EQUILIBRIO EN DISOLUCIÓN}

Teorías de Arrhenius e Bronsted-Lowry. Escala de pH. Ácidos/bases fortes/ débiles. lóns como ácidos/bases. Ácidos e bases de Lewis.

Efectos sobre o equilibrio ácido-base: ión común, disolucións reguladoras, neutralización e curvas de valoración.

Constante do produto de solubilidade. Precipitación.

\section{Unidade 6. ELECTROQUÍMICA}

Potenciais de electrodo, potenciais estándar e potenciais de célula.

Ecuación de Nerst. Pilas, baterías e células de combustible. Electrólise. Corrosión. 
Unidade 7. QUÍMICA ORGÁNICA E QUÍMICA MACROMOLECULAR

Introdución aos compostos orgánicos e as súas estruturas.

Alcanos, alquenos e alquinos. Hidrocarburos aromáticos. Alcois, fenois e éteres. Aldehidos e cetonas. Ácidos carboxílicos, ésteres, amidas e aminas. Introdución ao polímeros. 
ÍNDICE

\section{PRESENTACIÓN}

\section{OS OBXECTIVOS}

1. Obxectivos xerais da materia

2. Obxectivos específicos da unidade didáctica

\section{OS PRINCIPIOS METODOLÓXICOS}

\section{OS CONTIDOS BÁSICOS}

1. Introdución aos compostos orgánicos e as súas estruturas (1 sesión)

2. Clases de compostos orgánicos, grupos funcionais e isomerìas (4 sesións)

3. Polímeros e materiais poliméricos (1 sesión)

\section{AVALIACIÓN}

\section{ANEXOS}

BIBLIOGRAFÍA 


\section{PRESENTACIÓN}

A materia Química do Grao en Física forma parte con Bioloxía e Informática para científicos do módulo de Formación básica de contido transversal e, á par destas, ten unha duración de 6 créditos ECTS. Impártese no segundo cuadrimestre do primeiro curso da titulación, polo que os alumnos dispoñen, na mellor das hipóteses, só dos coñecementos básicos de Química adquiridos no bacharelato (sempre que cursasen a modalidade "ciencia e tecnoloxía") o só se enfrontaron a ela na introdución a Física e a Química en terceiro, e eventualmente en cuarto, de educación superior obrigatoria. Elixiuse, polo tanto, un desenvolvemento dos contidos desde os temas máismáis sinxelos e básicos ata os máis prácticos e máis facilmente relacionables coa vida cotiá.

Despois de estudar na primeira unidade algúns conceptos básicos e terminolóxicos da química e das propiedades da materia, introdúcense as reaccións químicas e o concepto de enlace químico (respectivamente nas unidades no. 2 e 3), para pasar finalmente as últimas catro unidades, que poñen as bases dos alicerces de la química como son o equilibrio químico, a electroquímica e a química orgánica e macromolecular.

Esta unidade didáctica dedicada á introdución dos compostos orgánicos e dos polímeros está deseñada para ser desenvolvida en 7 sesións presenciais de 55 minutos cada unha. Delas, 4 sesións dedicaranse a clases expositivas, nas que se explican os contidos, 2 sesións utilizaranse para resolver exercicios e problemas e 1 sesión de titorías para aclarar cuestións puntuais. O alumno deberá dedicar unhas 12 horas adicionais de traballo persoal, fundamentalmente para a realización de exercicios e problemas adicionais.

\section{OS OBXECTIVOS}

\section{Obxectivos xerais da materia}

Perséguese que o alumnado adquira un nivel de coñecementos teóricos e experimentais básicos en Química, así coma a súa relación ca Física. Trátase de coñecer o impacto da Química na Física e viceversa. Comprender a importancia da aplicación dos coñecementos da Física nesta rama afín de coñecemento e do campo de aplicación na investigación tanto na súa faceta teórica coma experimental.

Tras cursar esta materia o alumnado deberá:

- coñecer e comprender os conceptos básicos da Química, tales coma aspectos fundamentais de termodinámica clásica, de equilibrio químico, de enlace químico e da química orgánica, que serán de gran utilidade para materias de cursos posteriores do grao;

- estar familiarizado cos temas dos que se ocupa a Química, así coma cos métodos desenvolvidos por esta rama da ciencia para dar solución aos problemas aos que se enfronta; 
- comprender o papel da Química dentro do panorama científico actual e coñecer a aplicación das leis da Química a casos particulares, así coma a súas limitacións.

\section{Obxectivos específicos da unidade didáctica}

Ao rematar a unidade didáctica o alumnado debe poder:

- clasificar os compostos orgánicos en función do seu grupo funcional. Enumerar os derivados do grupo carbonilo;

- diferenciar entre os distintos tipos de isómeros estruturais e de estereoisómeros. Identificar os isómeros cis-trans e determinar se un composto é quiral ou non;

- diferenciar entre polímero de adición e condensación;

- formular os polímeros máis comúns da química industrial.

\section{OS PRINCIPIOS METODOLÓXICOS}

Emprégase unha metodoloxía activa que supón a participación directa do alumnado en todo o proceso de ensino-aprendizaxe, coa realización de preguntas, coa realización das actividades habituais e a participación activa na corrección de problemas en clase, coa participación en actividades complementarias.

Os contidos da materia impartiranse nunha serie de clases expositivas, interactivas e de titorías, co apoio do es pazo organizativo da docencia ofrecido polo Campus Virtual:

- as CLASES EXPOSITIVAS impartiranse ao grupo completo e nelas daranse a coñecer ao alumno contidos fundamentais da materia. Ao comezo do tema exporase claramente o programa e os obxectivos principais do mesmo. Ao final do tema farase un breve resumo dos conceptos máis relevantes e proporanse novos obxectivos que permitirán interrelacionar contidos xa estudados cos do resto da materia e outras materias afíns. Durante a exposición de contidos proporanse problemas que exemplifiquen os conceptos desenvolvidos. Para facilitar o seguimento das clases polos alumnos, utilizarase o libro de texto Química General (Petrucci e outros, 2011), que ademais dispón dunha axuda en rede moi completa na paxina web da editorial do libro (Pearson Educación). Ademais recoméndase a consulta doutros libros de química xeral (Chang, 2010; Atkins e Jones, 2010; Domínguez Reboiras, 2006);

- as CLASES INTERACTIVAS impartiranse en grupo reducido e distribúense do xeito seguinte: (i) clases de encerado dedicadas á resolución de problemas e cuestións que clarifiquen os contidos desenvolvidos nas clases expositivas. Ao principio do tema darase ao alumno unha relación de problemas/cuestións co obxectivo de que intente a súa resolución previa ás clases; (ii) prácticas de laboratorio. 0 profesor entregará aos 
alumnos un guión ao principio do curso, de forma que os alumnos teñan tempo de preparar os conceptos teóricos e realizar os cálculos necesarios para levalas a cabo antes de chegar ao laboratorio. Os obxectivos que se perseguen con estas clases prácticas son que o alumno fixe conceptos teóricos aprendidos nas clases expositivas e interactivas, e, ao mesmo tempo, se familiarice co material de laboratorio e cos problemas prácticos que xorden ao planificar e desenvolver un experimento;

- as CLASES DE TITORÍAS impartiranse en grupos moi reducidos. As horas de titorías dedicaranse á resolución de exercicios un pouco máis complexos que os que se fan nas clases interactivas, onde o alumno teña que relacionar diferentes conceptos manexados durante o curso. Preténdese tamén mediante estas titorías facer un seguimento individualizado da aprendizaxe da materia. O alumnado disporá tamén das titorías convencionais para resolver dúbidas que xorden durante o estudio. Estas titorías faranse de forma presencial en horarios indicados polo profesor;

- a AULA VIRTUAL. Para facilitar o seguimento do tema compleméntase a formación presencial na clase a través dun conxunto de ferramentas que permitan desenvolver a aprendizaxe a través da rede. De xeito, o alumnado poderá descargar o material docente (presentacións, boletíns, etc.), realizar consultas a través do correo electrónico dedicado e consultar novidades respecto á organización ou desenvolvemento do tema.

\section{OS CONTIDOS BÁSICOS}

Para os químicos do século XIX a química orgánica consistía no estudo de compostos procedentes soamente da materia viva, á que se atribuía a "forza vital" necesaria para obter estes compostos. En 1928 o alemán F. Whöler sintetizou o primeiro composto orgánico nun laboratorio, a urea; desde entón os químicos descubriron ou sintetizaron varios millóns de compostos orgánicos.

Hoxe en día a química orgánica ou química do carbono é, máis en xeral, a rama da química que estuda unha clase numerosa de moléculas, naturais e sobre todo de sínteses, que conteñen carbono formando enlaces covalentes carbonocarbono ou carbono-hidróxeno, en combinación con menores cantidades de osíxeno, nitróxeno ou xofre. Os contidos desta unidade céntranse no exame dos tipos principais de compostos orgánicos e dividiranse en tres partes tal e como se detalla a continuación, cada unha desenvolvida nunha ou máis sesións de clase, incluíndo as clases expositivas e as interactivas. Móstranse tamén diapositivas representativas das presentacións utilizadas polo profesor, que van sempre acompañadas polo desenvolvemento dalgúns conceptos directamente ao encerado.

No anexo móstranse exemplos dos exercicios e problemas que os alumnos teñen que resolver durante as clases interactivas. 


\section{Introdución aos compostos orgánicos e as súas estruturas (1 sesión)}

Explícanse os distintos tipos de enlaces carbono-carbono, recórdanse as diferentes hibridacións do carbono tal e como estudado na unidade didáctica dedicada ao enlace químico e como estas afecten os ángulos de enlace. Ademais, estúdanse os tipos de formulas (empírica, molecular, semidesenvolvida, desenvolvida e estrutural) e representacións (en perspectiva, mixta e simplificada) máis frecuentemente usadas e que teñen que formar parte das ferramentas que os alumnos saiban utilizar (móstranse exemplos na diapositiva na Fig. 1).

Finalmente introdúcense de xeito moi xeral as diferentes familias de compostos orgánicos (Fig. 2), subliñando a importancia e a utilidade dalgunhas delas.

\section{Figura 1. Exemplo de diapositiva usada para explicar as diferentes formulas}

\section{Fórmulas e representacións}

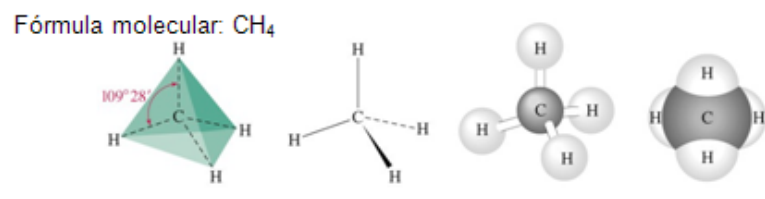

Representacións en perspectiva

Fórmula molecular: $\mathrm{C}_{4} \mathrm{H}_{10}$

Fórmula empírica: $\mathrm{C}_{2} \mathrm{H}_{5}$
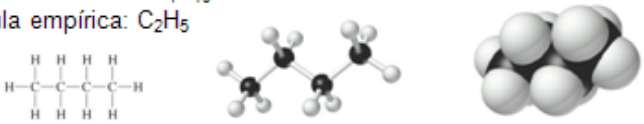

Fórmula desenvolvida ou expandida

Figura 2. Formula dalgúns compostos orgánicos

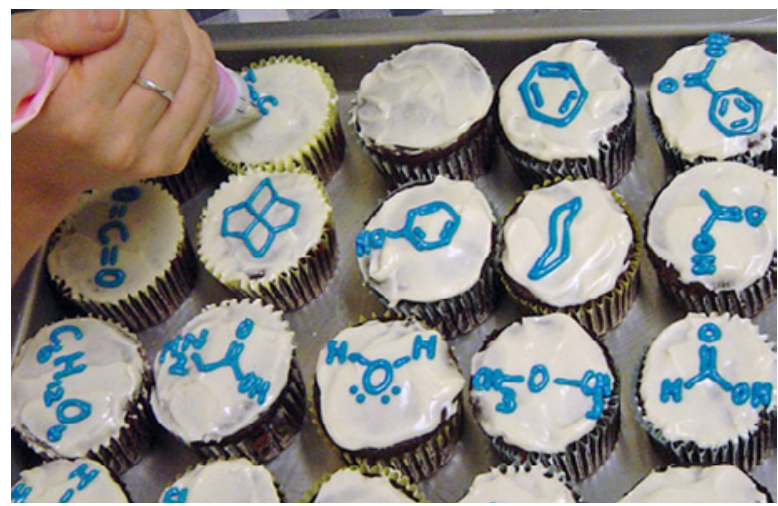

(imaxe da web: http://www.piecesbypolly.com/2013/10/organic-chemistry-cupcakes-for-mole-day.html). 


\section{Clases de compostos orgánicos, grupos funcionais e isomerìas (4 sesións)}

Nesta sección estúdanse as diferentes clases de compostos orgánicos, introdúcense as nomenclaturas de uso máis frecuente e as isomerías.

$\mathrm{Na}$ primeira sesión introdúcense e clasifícanse os hidrocarburos alifáticos: alcanos, alquenos, alquinos e estruturas cíclicas (na Fig. 3 móstrase unha das diapositivas usadas para introducir os cicloalcanos).

Figura 3. Cicloalcanos e as súas representacións

\section{Cicloalcanos}

Os alcanos cuxos átomos de $\mathrm{C}$ se unen en aneis coñécense como cicloalcanos. Teñen a fórmula xeral $\mathrm{C}_{n} \mathrm{H}_{2 n}$ onde $n=3,4, \ldots$
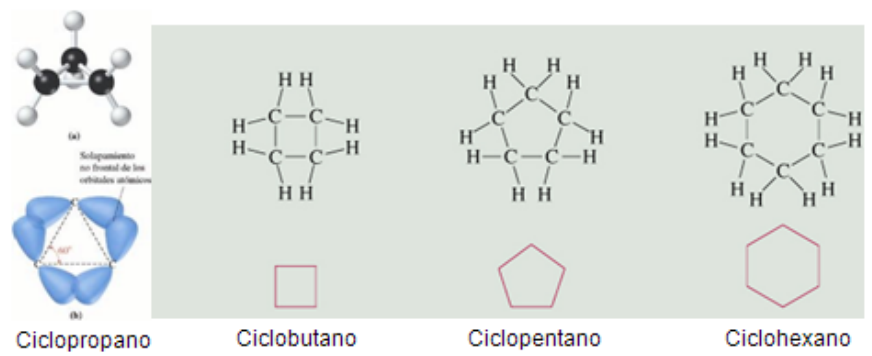

Ciclobutano

Ciclopentano

Ciclohexano

Representacións planas

Figura 4. Definición e exemplo de isomería estrutural nos alcanos

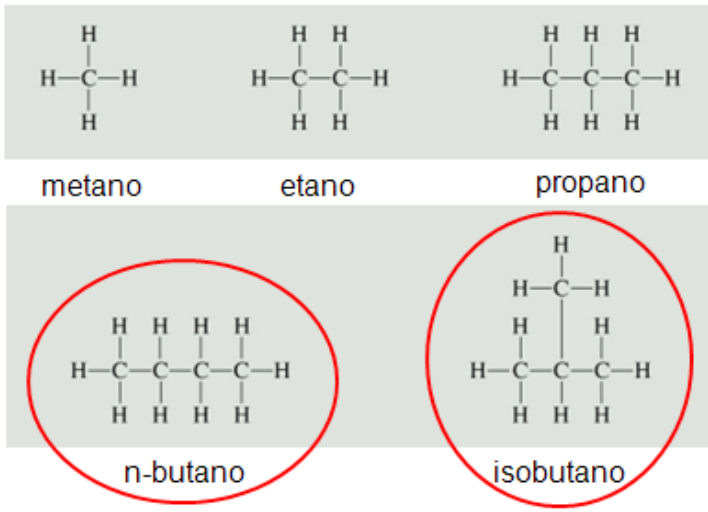

Isómeros planos ou estructurais son moléculas que teñen a mesma fórmula molecular pero diferente estructura. 
A continuación, aprovéitase das características estruturais dos alcanos para introducir o concepto de isomerías e máis especificamente explícanse a isomería estrutural (exemplo na Fig. 4), a isomería xeométrica, a isomería óptica (Fig. 5) e os conceptos de quiralidade e de actividade óptica.

Dedícase a primeira clase interactiva a exercicios de comprensión das isomerías (exemplo na Fig. 6) e practícase a nomenclatura dos hidrocarburos (exemplo en Fig. 7).

Figura 5. Carbono asimétrico e isomería óptica

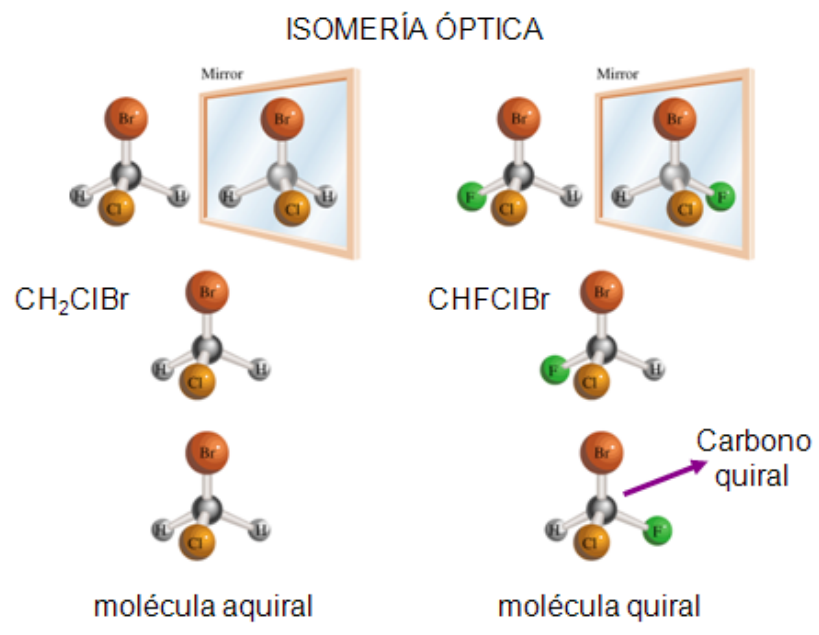

Figura 6. Exercicio de isomería estrutural (esta diapositiva ten animación que facilita o desenvolvemento do exercicio)

¿Cantos isómeros estructurais ten o pentano, $\mathrm{C}_{5} \mathrm{H}_{12}$ ?<smiles>CCCCC</smiles>

$n$-pentano

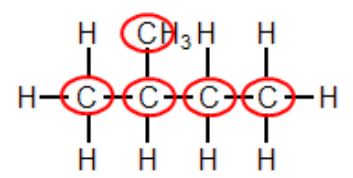<smiles>C=CC1CC(C)C(C)C1C</smiles>

2,2-dimetilpropano

2-metilbutano 
Figura 7. Exemplo de exercicio de nomenclatura dos alcanos substituídos (diapositiva con animación)

¿Cal é o nome IUPAC do seguinte composto?

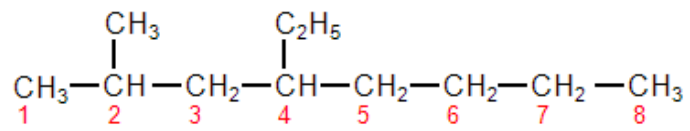

4-etil-2-metiloctano

¿Cal é a estructura do 4-etil-2,2-dimetilhexano?

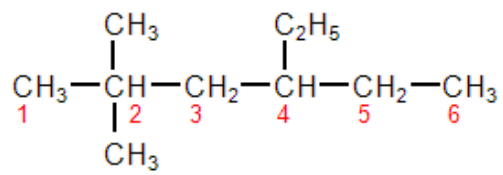

Os prefixos di-, tri-, tetra-,..., non entran na orde alfabética

Os primeiros químicos adoitaban asignar nomes aos compostos novos relacionados coas súas orixes ou con algunha das súas propiedades, pero ao irse sintetizando miles e miles de compostos novos fíxose evidente que este sistema era inviable. Hoxe en día a nomenclatura sistemática máis utilizada, que é tamén a que se estuda cos alumnos, é a recomendada pola Unión Internacional de Química Pura (IUPAC). De xeito, a seguinte clase dedícase aos hidrocarburos aromáticos, á nomenclatura dos compostos substituídos e á isomería de posición (Fig. 8).

Figura 8. Exemplo de nomenclatura e isomería de posición en compostos aromáticos substituídos

Nomenclatura de compostos aromáticos<smiles>Cc1ccc(I)cc1</smiles>

1,2-dibromobenceno o-dibromobenceno

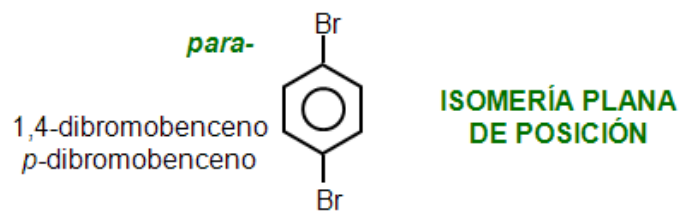

\section{1,3-dibromobenceno} $m$-dibromobenceno

SOMERÍA PLANA DE POSICIÓN 
Remátase o tema dos hidrocarburos mostrando de xeito moi xeral como se poden preparar alcanos e cales son as reaccións máis comúns tanto destes como dos alquenos e dos aneis aromáticos (exemplo na Fig. 9), recórdase ademais cal é a composición da fonte natural máis importantes de compostos orgánicos, o petróleo (Fig. 10).

Figura 9. Exemplo de reacción común dos aneis aromáticos: reacción de substitución aromática

Reaccións de sustitución aromática

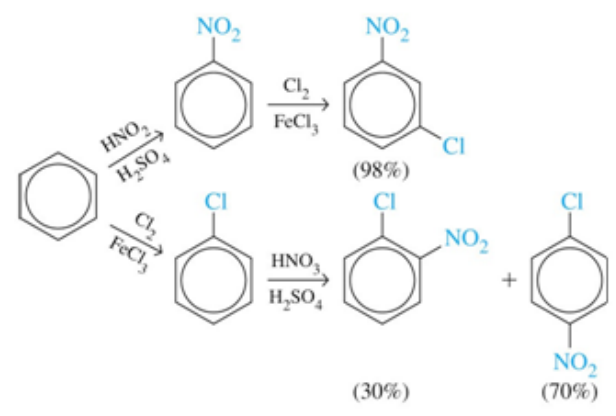

Figura 10. Aplicacións comúns, propiedades e composición das fraccións principais do petróleo

Fraccións principais do petroleo

\begin{tabular}{|l|l|c|}
\hline Fracción & Rango de ebullición $\left({ }^{\circ} \mathrm{C}\right)$ & $\begin{array}{l}\mathrm{n}^{\circ} \text { de átomos de } \\
\text { carbono }\end{array}$ \\
\hline Gas & Menor a 40 & 1 a 4 \\
\hline Gasolina & 40 a 200 & 5 a 12 \\
\hline Queroseno & 200 a 300 & 12 a 15 \\
\hline Gasóleo ou gasoil & 300 a 400 & 15 a 18 \\
\hline Aceites lubricantes & 300 a 370 & 16 a 20 \\
\hline Parafina sólida & $\begin{array}{l}\text { Mayor de } 400 \\
\text { Por destilación al vacio }\end{array}$ & 20 y más \\
\hline $\begin{array}{l}\text { Asfalto e carbón } \\
\text { coque }\end{array}$ & $\begin{array}{l}\text { Residuos sólidos } \\
\text { (no volátiles) }\end{array}$ & Mayor a 40 \\
\hline
\end{tabular}

Nas dúas ultimas sesións, unha expositiva, a outra interactiva, estúdase a química dos grupos funcionais. De cada clase, é dicir alcois, éteres, aldehidos, cetonas, ácidos carboxílicos, ésteres e aminas, estúdanse as características estruturais e as propiedades e introdúcense a nomenclatura (exemplos nas Fig. 11 e 12) e algunhas reaccións de conversión dun grupo funcional noutros (exemplo na Fig. 13), sempre intentando relacionar as diferentes familias coa realidade cotiá e industrial. Os 
exercicios céntranse na nomenclatura e no recoñecemento dos grupos funcionais e de todas as isomerías estudadas nesta sección.

\section{Figura 11. Introdución á química dos alcois}

\section{Química dos grupos funcionais}

Alcohois conteñen un grupo funcional hidroxilo, $-\mathrm{OH}_{\text {, e teñen a }}$ fórmula xeral $\mathrm{R}-\mathrm{OH}$.

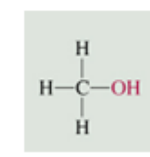

metanol (alcohol metílico)

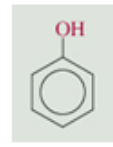

fenol

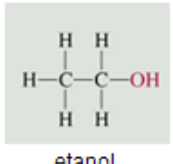

alcohol etílico)

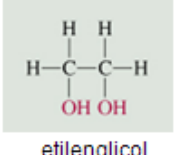

etilenglicol

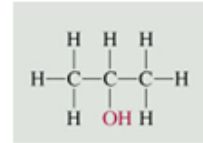

2-propanol (alcohol isopropilico)

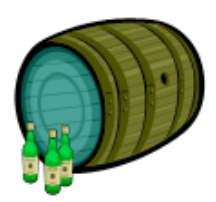

Figura 12. Introdución á química dos aldehidos e cetonas Química dos grupos funcionais

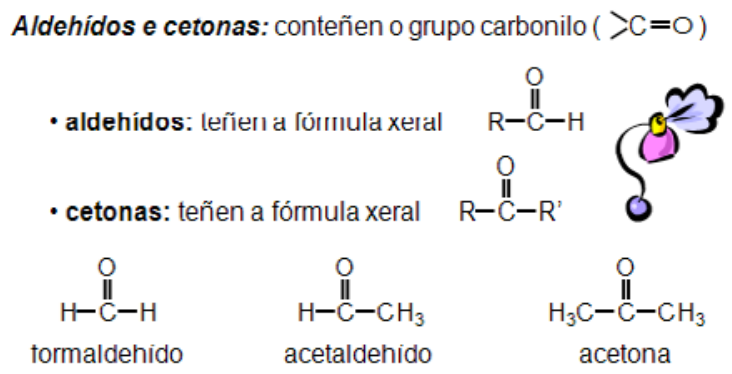


Figura 13. Reaccións de transformación do propileno en compostos con outros grupos funcionais (diapositiva dobre).

De cada composto descríbese a importancia a nivel industrial e as posibles aplicacións e outros xeitos de sintetizalos

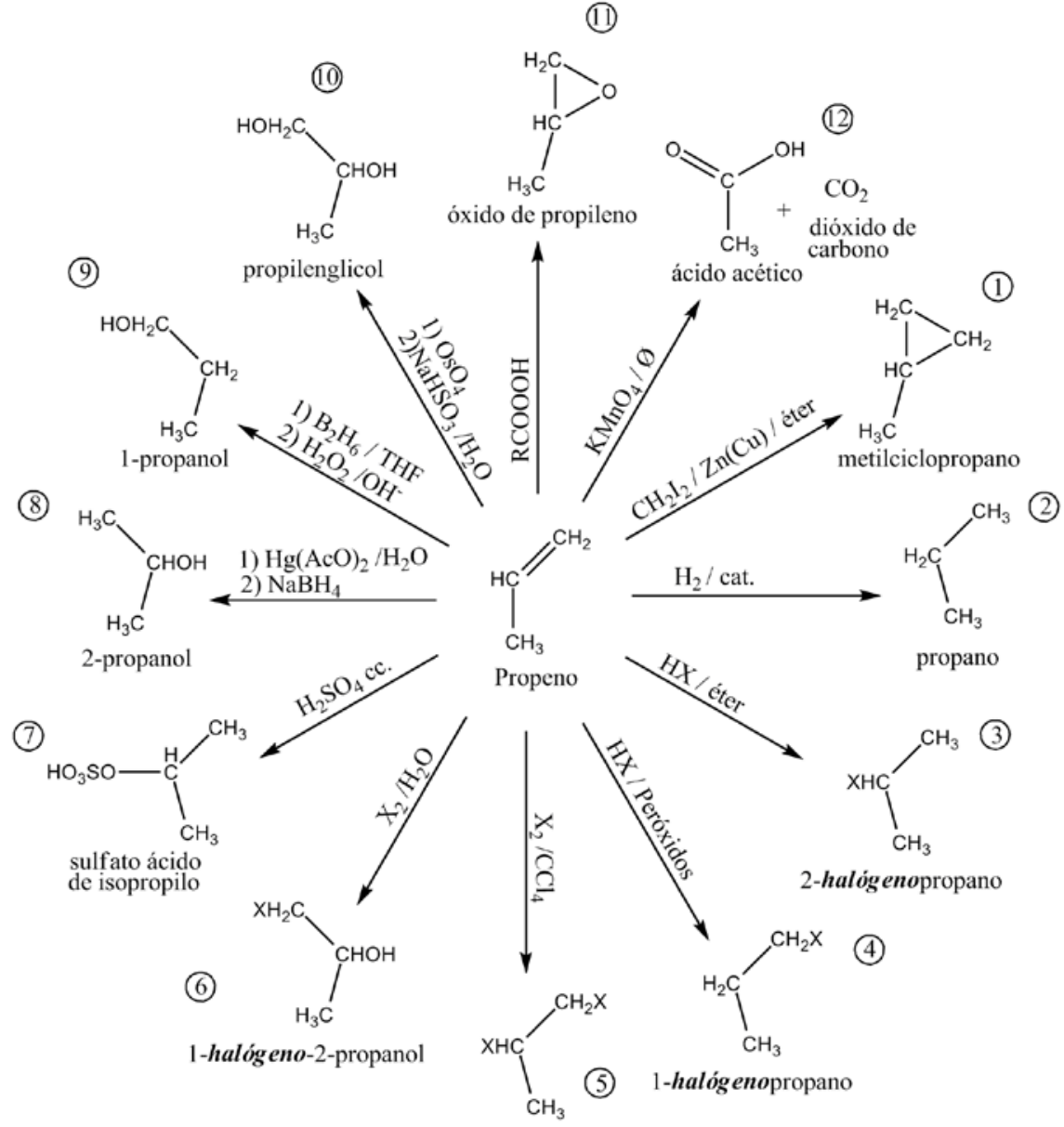

1,2-dihalógenopropano

\section{Polímeros e materiais poliméricos (1 sesión)}

Nesta ultima parte da unidade didáctica dedicada aos polímeros empézase cunha introdución dos conceptos básicos (definición na Fig. 14), para pasar logo á súa clasificación segundo a orixe, estrutura, composición, síntese e cinética de polimerización (Fig. 15), comportamento térmico e uso [plastómeros, elastómeros, fibras, adhesivos, recubrimentos, etc.]. 
Figura 14. Polímeros: conceptos básicos

Polímero ( $\pi \circ \lambda_{2} \mu$ sowo muchas partes)

molécula xigante, macromolécula, constituída por unha multitude de unidades *repetitivas, unidades monoméricas, unidas por enlaces covalentes

peso molecular: $10^{3}-10^{7} \mathrm{~g} / \mathrm{mol}$

\section{Monómero}

molécula pequena capaz de reaccionar con outras

molécula iguais, ou parecidas, para dar un polímero

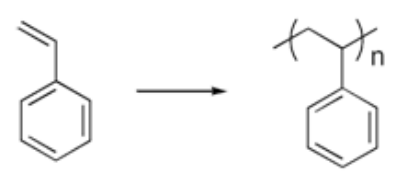

Figura 15. Clasificación segundo a cinética de polimerización e a síntese

\section{Clasificación de polímeros (síntese)}

Polímeros por adición (polimerización en cadena)

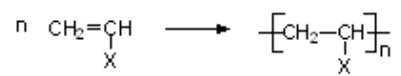

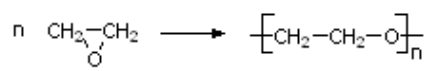

\section{Polímeros por condensación (polimerización por etapas)}

Nylon 6,8

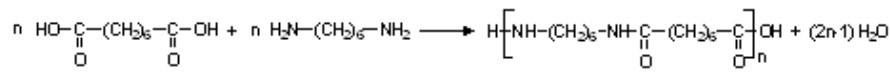

Estúdanse tamén algunhas propiedades como as propiedade térmicas e mecánicas (exemplo na Fig. 16) e preséntanse as aplicacións industriais máis importantes das clases comúns de polímeros, así como algunhas aplicacións tecnolóxicamente avanzadas de nanomateriales poliméricos (exemplo na Fig. 17). Ao final da unidade trataranse de xeito moi xeral algúns aspectos da fabricación, consumo e reciclaxe de materiais polimericos. 
Figura 16. Exemplo de propiedades peculiares de polímeros: a transición vítrea. Compárase esta propiedade coa temperatura de cristalización e sublíñanse os factores comúns que afectan as dúas

\section{Temperatura de transición vítrea}

Desde segmentos da cadea polimérica conxelados a unha situación con movementos moleculares de longo alcance

(sólido vítreo $\rightarrow$ estado líquido)

coa Tg varían: calor específica, volumen específico, modulo elástico, etc.

depende da natureza química:

- flexibilidad

- simetría

- polaridad (forza intermoleculares)

e de factores externos:

- pesomolecular

- diluyentes ou plastificantes

- reticulación

- introdución de comonómeros

Figura 17. Explicación do concepto de nanocomposto e introdución ás propiedades a nivel micro e nanométrico. Diapositiva con animación na que se mostran tamén exemplos dos obxectos comerciais realizados usando estes materiais

\section{Nanocomposto polímerico}

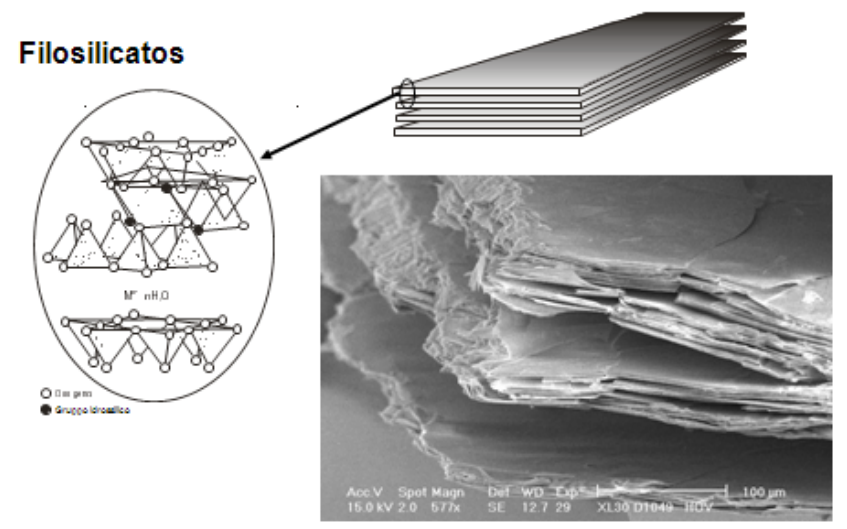




\section{AVALIACIÓN}

A avaliación desta unidade didáctica realizarase dentro dunha metodoloxía xeral de avaliación da materia. O sistema de avaliación baséase na formación continua do alumno. Valorarase o traballo diario do alumno e para isto farase un seguimento do mesmo. As dimensións avaliadas dentro dos temas de cada unidade didáctica expóñense a continuación:

- asistencia ás clases expositivas, interactivas, titorías e prácticas;

- participación activa nas clases interactivas de encerado (resolución dos problemas propostos nos boletíns, discusión dos resultados, etc...);

- a exposición e discusión dos temas propostos para as clases de titorías;

- realizar os test que se propoñan.

O cómputo destas actividades de avaliación continua na cualificación final será do $40 \%$ (nota $\mathrm{AC}$ ), dentro da que se contemplarán a avaliación das actividades desenvoltas nesta UD. Ademais os alumnos realizarán un exame (ben ordinario, realizado a finais de maio,ou ben extraordinario, realizado en xullo) que computará o $60 \%$ restante da cualificación final (nota EX) e que contará con preguntas específicas desta UD.

Establécese unha puntuación mínima neste exame dun 3 sobre 10 para poder realizar a media coa nota da avaliación continua. A cualificación do alumno non será inferior a do exame final, nin a obtida ponderada coa avaliación, polo tanto a nota final será a máis alta de:

- nota EX;

- 0,6 x nota $E X+0,4 \times$ nota $A C$. 


\section{ANEXOS}

A continuación móstrase un exemplo de boletín que contén exercicios e problemas que os estudantes teñen que intentar resolver pola súa conta e, no seu caso, resólvense durante as clases interactivas.

\section{Boletin tema 9}

1) Indique un nome aceptable de cada un dos seguintes compostos:
$\mathrm{CH}_{3} \quad \mathrm{CH}_{3}$
(a) $\mathrm{CH}_{3} \mathrm{CH}_{2} \mathrm{CH}_{2} \mathrm{CHCH}_{2} \mathrm{CHCH}_{2} \mathrm{CH}_{3}$
(b) $\begin{gathered}\mathrm{CH}_{3}-\mathrm{C}-\mathrm{CH}_{3} \\ \mathrm{CH}_{3}\end{gathered}$
(c) $\mathrm{CH}_{3} \mathrm{CH}_{2} \mathrm{CHCH}_{2}-I_{\mathrm{C}}^{\mathrm{Cl}}-\mathrm{CH}_{2} \mathrm{CH}_{3}$

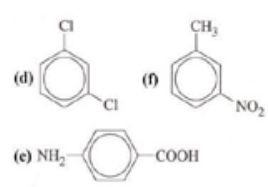

2) Escriba fórmulas desenvolvidas correspondentes ás seguintes fórmulas semidesenvolvidas:
(a) $\mathrm{CH}_{3} \mathrm{CH}_{2} \mathrm{CHBrCHBrCH}_{3}$
(b) $\left(\mathrm{CH}_{3}\right)_{3} \mathrm{CCH}_{2} \mathrm{C}\left(\mathrm{CH}_{3}\right)_{2} \mathrm{CH}_{2} \mathrm{CH}_{2} \mathrm{CH}_{3}$
(c) $\left(\mathrm{C}_{2} \mathrm{H}_{5}\right)_{2} \mathrm{CHCH}=\mathrm{CHCH}_{2} \mathrm{CH}_{3}$

3) Escriba fórmulas desenvolvidas dos seguintes compostos:
(a) 3-isopropiloctano;
(b) 2-cloro-3-metilpentano;
(c) 2-penteno;
(d) dipropil éter;
(e) p-bromofenol

4) Que hidrocarburo ten un maior número de isómeros, $\mathrm{C}_{4} \mathrm{H}_{8}$ o $\mathrm{C}_{4} \mathrm{H}_{10}$ ? Xustifique a súa resposta.

5) Isómeros estruturais, de posición, xeométricos. Que termino describe mellor cada unha das seguintes parellas de isómeros?

(a) $\mathrm{CH}_{3} \mathrm{CH}_{2} \mathrm{CH}_{2} \mathrm{Cl}_{\text {y CH}} \mathrm{CHClCH}_{3}$

(b) $\mathrm{CH}_{3} \mathrm{CH}\left(\mathrm{CH}_{3}\right) \mathrm{CH}_{2} \mathrm{CH}_{3}$ y CH $\mathrm{CH}_{3}\left(\mathrm{CH}_{2}\right)_{3} \mathrm{CH}_{3}$

(c)<smiles>Cc1cccc(N)c1</smiles>

(d) $\mathrm{CHCl}=\mathrm{CHCl}$ y $\mathrm{CH}_{2}=\mathrm{CCl}$,

(e) $\mathrm{CH}_{2}=\mathrm{CHCH}_{2} \mathrm{CH}_{3}$ y $\mathrm{CH}_{2}=\mathrm{C}\left(\mathrm{CH}_{3}\right)_{2}$

6) Escriba e nome todos os isómeros de (a) $\mathrm{C}_{6} \mathrm{H}_{14}$; (b) $\mathrm{C}_{4} \mathrm{H}_{8}$; (c) $\mathrm{C}_{4} \mathrm{H}_{6}$. (Stcxestión: non esqueza os dobre enlaces, os ciclos e as combinacións de ambos)

7) Identifique o grupo funcional en cada composto (é dicir, si é un alcohol, unha amina, etc.):
(a) $\mathrm{CH}_{3} \mathrm{CHBrCH}_{2} \mathrm{CH}_{3}$
(c) $\mathrm{C}_{6} \mathrm{H}_{5} \mathrm{CH}_{2} \mathrm{CHO}$
(b) $\mathrm{CH}_{3} \mathrm{CH}_{2} \mathrm{COOH}$
(e) $\mathrm{CH}_{3} \mathrm{COCH}_{2} \mathrm{CH}_{3}$
(d) $\left(\mathrm{CH}_{3}\right)_{2} \mathrm{CHCH}_{2} \mathrm{OCH}_{3}$
(g) $\mathrm{C}_{6} \mathrm{H}_{4}(\mathrm{OH})_{2}$
(f) $\mathrm{CH}_{3} \mathrm{CH}\left(\mathrm{NH}_{2}\right) \mathrm{CH}_{2} \mathrm{CH}$
(h) $\mathrm{CH}_{3} \mathrm{COOCH}_{3}$

8) Identifique e nome os grupos funcionais dos seguintes compostos:<smiles>CCOC(C)=O</smiles><smiles>CC(=O)CCC(=O)O</smiles>

(d)<smiles>O=Cc1cccc(O)c1</smiles> 


\section{BIBLIOGRAFÍA}

ATKInS, P. W. e L. Jones, (2010): Principios de Química, Editorial Médica Panamericana, 5a Edición.

CHANG R. (2010): Química, McGraw Hill, 10a Edición.

Domínguez Reboiras, M. A. (2006): Química: La ciencia básica, Thomson Editores.

Petrucci, R. H., F. G. Herring, J. D. Madura e C. Bissonnette (2011): Química General, Pearson Educación, 10a Edición.

Recursos para estudantes na internet (MasteringChemistry, na páxina de Pearson Educación) ${ }^{1}$ : http://www.pearsonmylabandmastering.com/global/

1 MasteringChemistry é unha ferramenta de aprendizaxe interactiva e online que ofrece contidos e modalidades de estudo personalizado. Axuda aos alumnos no seu proceso de aprendizaxe, guiándolles paso a paso na resolución dos exercicios, e ofrecendo recursos extra para a súa consulta. 


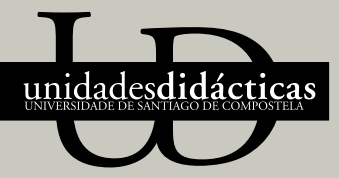

Unha colección orientada a editar materiais docentes de calidade e pensada para apoiar o traballo do profesorado e do alumnado de todas as materias e titulacións da universidade 